\title{
Neck Circumference as an alternative anthropometric measure of obesity in patients of Type 2 Diabetes Mellitus - A Hospital Based Study
}

\author{
Dr. Nida Nowreen ${ }^{1}$, Dr. Sonika Sangra ${ }^{2}$, Dr. Sunil Sachdev ${ }^{3}$ \\ ${ }^{I}$ P.G. Scholar, Department of Physiology, Government Medical College, Jammu, J\&K, India \\ ${ }^{2}$ P.G. Scholar, Department of Community Medicine, Government Medical College, Jammu, J\&K, India \\ ${ }^{3}$ Professor and Head, Department of Physiology, Government Medical College, Jammu, J\&K, India
}

\begin{abstract}
Background: Type 2 diabetes mellitus is an endocrine as well as a metabolic disorder. Obesity is not only the most common cause of insulin resistance, but also a growing health concern in its own right. There are a number of conventional methods to assess obesity with neck circumference being a relatively newer method.

Objective: The present study was aimed at evaluating the correlation of the neck circumference with other anthropometric parameters in patients of type 2 diabetes mellitus.

Methodology: A cross-sectional study was carried out in 100 patients of type 2 diabetes mellitus to investigate the correlation of the neck circumference with BMI, WC, and W/H ratio.

Results: Neck circumference (NC) has shown a strong positive correlation with BMI, in both male and female type-2 diabetics $(r=0.882$ for men and $r=0.956$ for women, $p<0.0001$ in both). In both genders very high values were obtained for the coefficient of determination $\left(R^{2}=0.777\right.$ in males and $R^{2}=0.913$ in females). NC has also shown a positive correlation with WC, HC and WHR in both male and female type-2 diabetics $(r=$ $0.802, r=0.662, r=0.58$ for males and $r=0.817, r=0.749, r=0.522$ for females, respectively with $p$-value $<0.0001$ in all parameters).

Conclusion: Our study has demonstrated a positive correlation between neck circumference, which is a simple and fast anthropometric measurement, BMI and other anthropometric measures like waist circumference in patients of type 2 diabetes mellitus.
\end{abstract}

Keywords: Type 2 diabetes mellitus, Neck circumference, waist circumference, obesity

\section{Introduction}

Type 2 diabetes mellitus is an endocrine as well as a metabolic disorder. The interaction between several genetic and environmental factors results in the development of this heterogeneous and progressive disorder with varying degrees of insulin resistance and pancreatic $\beta$-cell dysfunction. Among the major contributors to the development of insulin resistance and impaired glucose tolerance are overweight and obesity .$^{1,2,3}$ Obesity is not only the most common cause of insulin resistance, but also a growing health concern in its very own right. ${ }^{4}$ Different anthropometric measurements are used throughout the world to determine obesity or central obesity. These are the body mass index (BMI), waist circumference (WC) and waist-to-hip ratio $(\mathrm{W} / \mathrm{H}){ }^{5}$ BMI is a useful measurement of overall obesity but for determining central obesity, WC, which demonstrates the existence of abdominal visceral fat more accurately, is applied. ${ }^{6}$ The use of WC has some limitations. First of all, it requires removal of clothes and the convenience of proper temperature. The second one is that it may vary throughout the day based on whether the person has had meals. The third one is that it may vary in case of certain health problems affecting the abdominal wall. The fourth one is that some people may not allow the measurement with light clothes due to religious and cultural reasons. ${ }^{7}$ In recent years, neck circumference (NC), which is an easier and faster anthropometric measurement, has been defined to determine central obesity. ${ }^{8}$ In community-based studies, it has been demonstrated that there is a positive correlation between $\mathrm{NC}$ and metabolic risk factors, insulin resistance and visceral adipose tissue, and that it is an independent determinant for the cardiometabolic syndrome ${ }^{9,10}$ Data about the relation of NC as an indicator of upper abdominal obesity with cardio-metabolic risk factors is lacking. Most of the studies in this field have been performed on normal population and there is not enough data available about high risk patients such as diabetic patients. ${ }^{11}$ In view of latter the present study was aimed at evaluating the correlation of the neck circumference with BMI, WC, W/H ratio in patients of type 2 diabetes mellitus.

\section{Material and Methodology}

A cross-sectional study was carried out in the Department of Physiology, Government Medical College, Jammu w.e.f. November 2013 to October 2014.One hundred Diagnosed cases of type-2 diabetes 
mellitus of variable duration aged 30 years and older (up to 68 years), were recruited for the study. The subjects were determined by "random" sampling. Written informed consent was obtained from all participants. Past medical history was determined with a standardized questionnaire. Anthropometric measurements such as height, weight, waist circumference, hip circumference, and neck circumference were made. Those with thyroid disease, Cushing's syndrome, lymphadenopathy, pregnant and lactating women, and physically handicapped persons were excluded from the study. Measurements were obtained in light clothes, fasting, standing, without shoes and at the end of expiration. Weight was measured using digital scale to the nearest $0.1 \mathrm{~kg}$ with only light clothing, and height was determined using a portable stadiometer to the nearest $1 \mathrm{~mm}$ barefoot. Waist circumference was taken horizontally to the nearest $1 \mathrm{~mm}$, using plastic tape measure at midpoint between the costal margin and iliac crest in the mid-axillary line. Hip circumference was measured at the level of greater trochanters with the legs close together. BMI was calculated as weight (kilogramme) divided by the square of height (meter). W/H ratio was calculated by dividing the waist circumference by the hip circumference. Neck circumference was measured mid way between mid cervical spine and mid anterior neck, horizontally (just below the laryngeal prominence), using non-stretchable plastic tape. The subject was asked to look straight ahead with shoulders down and relaxed, but not hunched. It was recorded in centimetres $(\mathrm{cm}) .{ }^{12}$ Height weight, BMI, waist-hip ratio was recorded as per standards recommended by WHO. ${ }^{13}$ All circumferences were taken with the subjects standing upright, with the face directed forwards and shoulders relaxed.

Data was analyzed using computer software MS Excel for windows and SPSS for Windows ver. 19. Results were expressed in mean \pm standard deviation. Chi-square and student's t-test were used wherever applicable. Correlation analysis was done using Karl Pearson's method. Coefficient of determination $\left(\mathrm{R}^{2}\right)$ was used to predict anthropometric variances in relation to neck circumference. A p-value of less than 0.05 was considered statistically significant.

\section{Results}

The study comprised of 100 diagnosed cases of type-2 diabetes mellitus (50 males and 50 females). Following observations were made during the course of study.

Table 1: Mean anthropometric parameters according to gender

\begin{tabular}{|l|l|l|l|}
\hline $\begin{array}{l}\text { Anthropometric } \\
\text { parameters }\end{array}$ & $\begin{array}{l}\text { Male }(\mathbf{n}=50) \\
\text { Mean } \pm \text { Standard } \\
\text { deviation }\end{array}$ & $\begin{array}{l}\text { Female }(\mathbf{n = 5 0}) \\
\text { Mean } \pm \text { Standard } \\
\text { deviation }\end{array}$ & p-value \\
\hline NC $(\mathrm{cm})$ & $38.96 \pm 3.149$ & $37.22 \pm 3.677$ & 0.013 \\
\hline BMI $\left(\mathrm{kg} / \mathrm{m}^{2}\right)$ & $27.16 \pm 3.678$ & $28.32 \pm 4.230$ & 0.004 \\
\hline WC $(\mathrm{cm})$ & $98.08 \pm 9.147$ & $91.68 \pm 12.087$ & 0.002 \\
\hline HC $(\mathrm{cm})$ & $100.28 \pm 7.46$ & $105.610 \pm 9.24$ & 0.0001 \\
\hline WHR & $0.97 \pm 0.059$ & $0.85 \pm 0.072$ & 0.147 \\
\hline
\end{tabular}

The above table depicts comparison of mean anthropometric parameters according to gender. By applying Student's t' test, it is observed that:

- Mean neck circumference (NC) in males is $38.96+3.149 \mathrm{~cm}$ and in females is $37.22+3.677 \mathrm{~cm}$. It is slightly higher in males and the difference is statistically significant $(\mathrm{p}=0.013)$.

- Mean body mass index (BMI) in males is $27.16 \pm 3.678 \mathrm{~kg} / \mathrm{m}^{2}$ and in females is $28.32 \pm 4.230 \mathrm{~kg} / \mathrm{m}$. It is higher in females than in males and the difference is statistically highly significant.

- Mean waist circumference (WC) in males is $98.08 \pm 9.147 \mathrm{~cm}$ and in females is $91.68 \pm 12.087 \mathrm{~cm}$. It is higher in males and the difference is statistically highly significant. This difference is due to the difference in male and female body types.

- Mean hip circumference (HC) in males is $100.28 \pm 7.46 \mathrm{~cm}$ and in females is $105.61 \pm 9.247 \mathrm{~cm}$. It is higher in females and the difference is statistically highly significant. This difference is again due to the difference in male and female body types.

- Mean waist-hip ratio in males is $0.97 \pm 0.059$ and in females is $0.85 \pm 0.072$. It is slightly higher in males but the difference is statistically non-significant.

Table 2: Correlation of neck circumference with other anthropometric parameters in male subjects $(n=50)$

\begin{tabular}{|l|l|l|l|l|}
\hline \multirow{2}{*}{$\begin{array}{l}\text { Anthropometric } \\
\text { parameters }\end{array}$} & \multicolumn{4}{|l|}{ Neck circumference (NC) } \\
\cline { 2 - 5 } & $\mathbf{r}$ & $\mathbf{R}^{2}$ & $\mathbf{p}$ & Statistical Inference \\
\hline BMI $\left(\mathrm{kg} / \mathrm{m}^{2}\right)$ & 0.882 & 0.777 & 0.0001 & HS \\
\hline WC $(\mathrm{cm})$ & 0.802 & 0.643 & 0.0001 & HS \\
\hline HC $(\mathrm{cm})$ & 0.662 & 0.438 & 0.0001 & HS \\
\hline WHR & 0.581 & 0.337 & 0.0001 & HS \\
\hline
\end{tabular}

NS = Non-significant HS =Highly Significant 
- Table 2 shows the relationship of neck circumference with other anthropometric parameters in male subjects.

- Body mass index (BMI): Neck circumference (NC) shows a positive correlation with BMI which is highly significant statistically $(\mathrm{r}=0.882, \mathrm{p}=0.0001)$. Values obtained for the coefficient of determination $\left(\mathrm{R}^{2}=0.777\right)$ indicate that $\mathrm{NC}$ can predict BMI with $77.7 \%$ of the variance in males.

- Waist circumference (WC): Neck circumference (NC) shows a positive correlation with WC which is highly significant statistically $(r=0.802, p=0.0001)$. Values obtained for the coefficient of determination $\left(R^{2}=0.643\right)$ indicate that $\mathrm{NC}$ can predict WC with $64.3 \%$ of the variance in males.

- Hip circumference (HC): Neck circumference (NC) shows a positive correlation with HC which is highly significant statistically $(\mathrm{r}=0.662, \mathrm{p}=0.0001)$. Values obtained for the coefficient of determination $\left(\mathrm{R}^{2}=0.438\right)$ are low and indicate that only $43.8 \%$ of the variance in $\mathrm{HC}$ can be explained by NC in males.

- Waist-hip ratio (WHR): Neck circumference (NC) shows a positive correlation with WHR which is highly significant statistically $(r=0.581, p=0.0001)$. Values obtained for the coefficient of determination $\left(\mathrm{R}^{2}=0.337\right)$ are low and indicate that only $33.7 \%$ of the variance in waist-hip ratio can be explained by NC in males.

Table 3: Correlation of neck circumference with other anthropometric parameters in female subjects $(n=50)$

\begin{tabular}{|l|l|l|l|l|}
\hline \multirow{2}{*}{$\begin{array}{l}\text { Anthropometric } \\
\text { parameters }\end{array}$} & \multicolumn{4}{|l|}{ Neck circumference (NC) } \\
\cline { 2 - 5 } & $\mathbf{r}$ & $\mathbf{R}^{2}$ & $\mathbf{p}$ & Statistical Inference \\
\hline BMI $\left(\mathrm{kg} / \mathrm{m}^{2}\right)$ & 0.956 & 0.913 & 0.0001 & HS \\
\hline WC $(\mathrm{cm})$ & 0.817 & 0.667 & 0.0001 & HS \\
\hline HC $(\mathrm{cm})$ & 0.749 & 0.561 & 0.0001 & HS \\
\hline WHR & 0.522 & 0.272 & 0.0001 & HS \\
\hline
\end{tabular}

- Table 3 shows the relationship of neck circumference with other anthropometric parameters in female subjects.

- Body mass index (BMI): Neck circumference (NC) shows a positive correlation with BMI which is highly significant statistically $(r=0.956, p=0.0001)$. Values obtained for the coefficient of determination $\left(R^{2}=0.913\right)$ indicate that $\mathrm{NC}$ can predict BMI with $91.3 \%$ of the variance in females.

- Waist circumference (WC): Neck circumference (NC) shows a positive correlation with WC which is highly significant statistically $(r=0.817, p=0.0001)$. Values obtained for the coefficient of determination $\left(R^{2}=0.667\right)$ indicate that $\mathrm{NC}$ can predict WC with $66.7 \%$ of the variance in females.

- Hip circumference (HC): Neck circumference (NC) shows a positive correlation with HC which is highly significant statistically $(r=0.749, p=0.0001)$. Values obtained for the coefficient of determination $\left(\mathrm{R}^{2}=0.561\right)$ indicate that $\mathrm{NC}$ can predict $\mathrm{HC}$ with $56.1 \%$ of the variance in females.

- Waist-hip ratio (WHR): Neck circumference (NC) shows a positive correlation with WHR which is highly significant statistically $(\mathrm{r}=0.522, \mathrm{p}=0.0001)$. Values obtained for the coefficient of determination $\left(\mathrm{R}^{2}=0.272\right)$ are low and indicate that only $27.2 \%$ of the variance in waist-hip ratio can be explained by $\mathrm{NC}$ in females.

\section{Discussion}

Diabetes mellitus (DM) and obesity has a complex relationship, with type-2 diabetes being strongly associated with obesity. Obesity is associated with several risk factors for the later cardiovascular and metabolic disturbances in diabetes. ${ }^{14}$ Obesity, particularly when it occurs in upper part of body, is a major health risk. ${ }^{15}$ There are numerous methods of assessing overweight and obesity. Body mass index (BMI) is the most used method of determing obesity, but BMI does not account for factors such as distribution of body fat, specifically abdominal obesity and cannot differentiate between lean and fat body mass. ${ }^{12}$ Other procedures, such as ultrasound, computed tomography and magnetic resonance imaging are primarily used for research work and are quite costly.$^{16}$

The neck circumference is more accurate measure of central obesity (fat around the abdomen) than BMI because of the strong correlation between high neck circumference measurements and central adiposity.$^{17}$ Neck circumference (NC) measurement is an easy and simple screening measure, as an index of upper body fat distribution that can be used to identify overweight and obese people. Neck circumference is being investigated as a screening instrument for overweight individuals because it is easy to measure, inexpensive, non-invasive, and unlike waist circumference, it does not vary throughout the day and is more practical and convenient during winter. $^{18}$

In the present study, neck circumference (NC) has shown a strong positive correlation with BMI, in both male and female type- 2 diabetics $(r=0.882$ for men and $r=0.956$ for women, $\mathrm{p}<0.0001$ in both). In both genders very high values were obtained for the coefficient of determination $\left(R^{2}=0.777\right.$ in males and $R^{2}=0.913$ in females) indicating that $\mathrm{NC}$ can predict BMI with $77.7 \%$ of the variance in males and $91.3 \%$ of variance in females. NC has also shown a positive correlation with WC, HC and WHR in both male and female type-2 
diabetics $(r=0.802, r=0.662, r=0.58$ for males and $r=0.817, r=0.749, r=0.522$ for females, respectively with $\mathrm{p}$-value $<0.0001$ in all parameters).

Our study is in accordance with Aswathappa et $a l^{8}$, who conducted a cross-sectional study, in a south Indian population (both diabetic and non-diabetics) and showed a high positive correlation between NC and BMI. The study also showed a high correlation between NC and WC, HC and WHR and also that mean NC was more in diabetic subjects as compared to non-diabetic subjects, which indicated that more of regional adiposity was present in type-2 diabetics. Our study is in agreement with the results of Beijing Community Diabetes Study, in which NC had a strong positive correlation with BMI in both genders. ${ }^{19}$ In a study conducted by Laakso et $a l^{20}$, neck circumference correlated strongly with the BMI in both genders. Neck circumference correlated with the WHR and waist circumference. Though the correlation was significant but the predictability of BMI using neck circumference was weak. This study was conducted in elderly non-diabetics in Finland. This disagreement may be due to differences in type of study sample and also due to demographic and ethnic differences.

Our study had some limitations like this study was conducted in a diabetic, cross-sectional population with a small sample size. There are no established guidelines to define anatomical location for neck circumference measurement, as there are for other anthropometric measurements.

\section{Conclusion}

Neck circumference measurement is a simple, time-saving, non-invasive and inexpensive screening measure that can be used to identify overweight and obesity in patients of type-2 diabetes.

As neck circumference has shown a high correlation with BMI it can be used as a potential alternative index for BMI or other anthropometric measures like waist circumference.

\section{References}

[1]. Stumvoll M, Goldstein BJ, van Haeften TW; Type 2 diabetes: principles of pathogenesis and therapy. Lancet.2005; 365 : $1333-46$.

[2]. Reaven GM, Role of insulin resistance in human disease. Diabetes; 1988; 37: 1595-607

[3]. Kahn SE, Hull RL, Utzschneider KM, Mechanisms linking obesity to insulin resistance and type 2 diabetes. Nature; 2006; 444: 840-46.

[4]. Goyal R, Faizy AF, Siddiqui SS, Singhai M. Evaluation of TNF- $\alpha$ and IL- 6 levels in obese and non-obese diabetics: Pre-.and postinsulin effects. N Am J Med Sci 2012;4:180-4.

[5]. Chan DC, Watts GF, Barrett PH, Burke V. Waist circumference, waist-to-hip ratio and body mass index as predictors of adipose tissue compartments in men. QJM. 2003 Jun;96(6):441-7.

[6]. Pouliot MC, Despres J, Lemieux S, Moorjani, S, Bouchard, C, Tremblay A, et al. Waist circumference and abdominal sagittal diameter: best simple anthropometric indexes of abdominal visceral adipose tissue accumulation and related cardiovascular risk in men and women. Am J Cardiol. 1994;73:460-8.

[7]. Wang J, Thornton JC, Bari S, Williamson B, Gallagher D, Heymsfield SB, et al. Comparisons of waist circumferences measured at 4 sites. Am J Clin Nutr. 2003 Feb;77(2):379-84.

[8]. Aswathappa J, Garg S, Kutty K, Shankar V. Neck circumference as an anthropometric measure of obesity in diabetics. N Am J Med Sci. 2013 Jan;5(1):28-31

[9]. Kumar NV, Ismail MH, Mahesha P, Girish M,Tripathy M. Neck circumference and cardio- metabolic syndrome. J Clin Diagn Res. 2014 Jul; 8(7):23-5.

[10]. Zhou JY, Ge H, Zhu MF, Wang LJ, Chen L, Tan YZ, et al. Neck circumference as an independent predictive contributor to cardiometabolic syndrome. Cardiovasc Diabetol. 2013 May 16;12:76.

[11]. Nafiu OO, Burke C, Lee J, Voepel-Lewis T, Malviya S, Tremper KK. Neck circumference as a screening measure for identifying children with high body mass index. Pediatrics 2010; 126: e306-10.

[12]. Ben-Noun L, Sohar E and Laor A. Neck circumference as a simple screening measure for identifying overweight and obese patients. Obes Res 2001; 9(8): 470-477.

[13]. WTRS. Physical status: the use and interpretation of anthropometry. WHO Technical Report Series 1995; 854: 427-433.

[14]. Fagot-Campagna A. Emergence of type-2 diabetes mellitus in children: epidemiological evidence. J Pediatr Endocrinol Metab 2000; 13 (Suppl 6): 1395-1402.

[15]. Hatipoglu N, Mazicioglu M, Kurtoglu L, Kendirci M. Neck circumference: an additional tool of screening overweight and obesity in chilhood. Eur J Pediatr 2010; 169: 733-39.

[16]. Preis SR, Massaro JM, Hoffmann U, D’Aqostino RB Sr, Levy D, Robins SJ, et al. Neck circumference as a novel measure of cardiometaboolic risk: the Framingham Heart study. J Clin Endocrinol Metab 2010; 95: 3701-10.

[17]. Ben-Noun LL and Laor A. Relationship between changes in neck circumference and cardiovascular risk factors. Exp Clin Cardol 2006; 11: 14-20.

[18]. Mazicioglu MM, Kurtoglu S, Ozturk A, Hatipoglu N, Cicik B, Ustunbas HB. Percentiles and mean values for neck circumference in Turkish children aged 6-18 years. Acta Paediatr 2010; 99(12): 1847-53.

[19]. Yang GR, Yuan SY, Fu HJ, Wan G, Zhu LX and Bu XL. Neck circumference positively related with central obesity, overweight, and metabolic syndrome in Chinese subjects with type-2 diabetes: Beijing Community Diabetes Study-4. Diab Care 2010; 33 : 2465-2467.

[20]. Laakso M, Matilainen V, Keinanen-Kiukaanniemi S. Association of neck circumference with insulin resistance-related factors. Int J Obesity 2002; 26(6): 873-75. 